\title{
O VERDADEIRO MUNDO DA CRECHE: EDUCAR OU PRESTAR ASSISTÊNCIA?
}

Drielly Adrean Batista, Rita Melissa Lepre, Rodrigo Cesar Costa , Aline kadooka.

Programa de pós-graduação em psicologia da Universidade Estadual Paulista “Júlio de Mesquita Filho" - UNESP-Assis. E-mail: driellyadrean@yahoo.com.br

\section{RESUMO}

O presente trabalho tem por objetivo mostrar por meio de um estudo teórico, alguns apontamentos a respeito da creche e de sua identidade, destacando características assistenciais, assistencialistas e educacionais presentes. A pesquisa buscou contextualizar o papel da creche no Brasil, e identificar se ela somente abriga crianças para que as famílias possam trabalhar ou se, alem do cuidar, ela tem o propósito de educar e desenvolver todas as suas habilidades do ser humano, contribuindo para a sua formação plena. Esse trabalho nos leva a uma grande reflexão sobre o dia a dia em creches, e ao final como é caracterizado sendo um ambiente onde somente se presta um assistencialismo ou também educa.

Palavras-chave: Creche. Educação Infantil. Práticas Pedagógicas. Assistencial. Assistência.

\section{INTRODUÇÃO}

Segundo Mello (2007) a creche assistencial esta envolvida na questão do educar voltado para a socialização da criança ou seja prestar assistência a educação integral dos indivíduos. Nessa perspectiva, a creche é um espaço de humanização direcionando suas praticas pedagógicas voltadas para a formação das relações interpessoais, da apropriação dos objetos da cultura oferecendo condições de que a criança desenvolva suas habilidades físicas e cognitivas. É necessário também proporcionar as crianças cuidados diários em relação a higiene e alimentação.

Devido as necessidades das famílias do século XX que não tinham com quem deixar seus filhos enquanto trabalham fora de casa, surge à creche dentro de um aparato assistencialista, para atender as necessidades oriundas da sociedade, ainda sem preocupação com a criança e seu desenvolvimento.

Atualmente em geral a creche realiza atividades diárias como: banho, hora do lanche, banho de sol, hora do sono, ela também tem em seu currículo questões educacionais ligadas a praticas pedagógicas voltadas ao processo de codificação ou memorização das letras, utilizandose de atividades mimeograficas sem valor, assim como jogos que se tornam métodos de ensino. A maioria das atividades são sem relevância para a criança, ocupando o tempo de outras atividades importantes como as brincadeiras, atividades artísticas entre outras. Com isso remete a importância de compreendemos esses aspectos que ainda existe nas creches de hoje. 


\section{A definição histórica da creche assistencialista no Brasil}

De acordo com Merisse 1997, no dia 17/11/1901, um grupo formado de professoras criam em São Paulo uma grande instituição de amparo e educação da infância e das mulheres em geral, onde o principal objetivo era destinado a formar educadoras para trabalharem em escolas ou instituições de caridade chamada de maternal (onde se referia a creche e jardim de infância). Com o passar do tempo foi se espalhando por toda a cidade. A partir daí foi se criando instituições voltadas as crianças onde seus pais trabalhavam o período integral e não tinham em hipótese nenhuma com quem deixar seus filhos, seus pais trabalhavam em fabricas onde era o forte daquela época.

Esse processo também teve muita influencia decorrente ao aumento cada vez maior das mulheres no mercado de trabalho, em busca de recursos melhores para sua sobrevivência que fez com que a busca por essas instituições aumentasse cada vez mais.

A historia das creches brasileiras marcada pelo assistencialismo corresponde também as modificações da sociedade onde há um contexto sócio político e cultural daquela época que inclui a expansão da industrialização e dos setores de serviços em escala crescente da urbanização.

Ainda de acordo com o autor, também sofria forte influencia religiosa em nível pedagógico, isso se correspondia à religião católica, onde tinha por base a educação tradicional.

Um dos aspectos da infância naquele período foi decorrente a proposta educacional, preparando as crianças pobres para o futuro. Assim como todo momento histórico, teve avanços, mas a creche de hoje ainda é vista por muitas pessoas com o principal objetivo de apenas cuidar, o educar é visto de um amaneira simplista, sem muitas preocupações com o desenvolvimento integral da criança.

\section{A realidade das creches nos dias atuais: 0 assistencialismo.}

A creche muitas vezes é vista como uma instituição social, cujo objetivo visa atender crianças filhos de pais trabalhadores, sem poder aquisitivos suficientes ou não tem com quem deixar seus filhos enquanto trabalham. Geralmente essas crianças são carentes tanto de carinho como de atenção, assim como também de coisas que são necessárias para a sua sobrevivência, como uma boa alimentação, roupas, sapatos, alem de produtos de higiene pessoal.

As instituições de educação infantil é um lugar onde se deve ter ações educativas para que as crianças se sintam bem, em um ambiente saudável e agradável. Vivendo essas ações presentes 
no seu dia a dia, e com medições potencializadas rumo ao pleno desenvolvimento, novas habilidades surgem as crianças decorrentes de suas experiências na creche.

Todas as relações com o mundo-ver, ouvir, cheirar, saborear, pensar, observar,sentir, desejar, agir, armar em suma, todos os órgãos da sua individualidade, como órgãos que são de forma diretamente comunal são em sua ação objetiva (sua ação em relação ao objeto) a apropriação desse objeto a apropriação da realidade humana (MELLO, 2007 p. 87)

A educação infantil é fundamental para o desenvolvimento da criança e de caminhada escolar. Nesse sentido, o papel da importância da dedicação das educadoras é essencial para a realização de um trabalho educativo significativo e intencional no espaço da creche. Na perspectiva da teoria histórica cultural a aprendizagem é que impulsiona o desenvolvimento, assim, se torna um aspecto importante para que os educadores reflitam nas condições de vida que se encadeia a qualidade humana para as crianças na educação infantil. O papel dos educadores é compreender as necessidades infantis e serem capazes de perceber que seu papel é essencial no processo educativo e conseqüentemente no processo de humanização.

A teoria histórico cultural vê o ser humano e sua humanidade como produtos da historia. No processo de criar e desenvolver a cultura, o ser humano formou sua esfera motriz- o conjunto dos gestos adequados ao uso dos objetos e dos instrumentos, e com a esfera motriz, criou também as funções intelectuais envolvidas nesse processo. (MELLO, 2007 p.86)

Quando a criança esta na creche é um momento que ela sente a necessidade de se relacionar com outras crianças e adultos, momento importante para a realização da mediação dos educadores em fazer com que sintam queridas, apoiadas e confiante, contribuindo também com a aquisição do desenvolvimento da linguagem.

Em relação à organização das rotinas diárias da creche, faz com que no seu dia a dia acabam utilizando-se de um tradicionalismo profundo. Podemos verificar essa questão através de um exemplo da rotina de uma creche municipal, segundo (ARANHA 1993, p.13).

Período da manhã:

$>\quad$ Trocas de roupas e organização das bolsas

$>\quad$ Banho de sol

$>\quad$ Higiene para o almoço

$>\quad$ Almoço

$>\quad$ Higiene após o almoço

Período da tarde: 


\author{
Repouso \\ Lanche \\ Banho \\ Estimulação individual \\ Janta \\ Saída
}

Podemos observar que com essa rotina fixa ao longo do dia fica difícil desenvolver outras atividades que venham a estimular as habilidades das crianças, atividades estimuladoras para o desenvolvimento da coordenação motora, da imaginação, e conseqüentemente a realização de atividades coletivas importantes para a socialização como podemos destacar a própria atividade do brincar.

Para Vygotsky, o brincar é atividade essencial para o desenvolvimento da criança, é um momento em que ela pode representar através do simbólico, aspectos presentes em sua realidade. No ato de brincar a criança vivencia e concretiza situações que, geralmente já viveu ou ainda vive, seja em seu contexto cotidiano ou seja em sua fantasia desejada, pois, na infância a imaginação, a fantasia, o brinquedo não são atividades que podem se caracterizar apenas pelo prazer que proporcionam. Para a criança o brincar é uma necessidade para seu desenvolvimento tanto cognitivo como para a socialização com o mundo.

É no brinquedo que a criança aprende a agir numa esfera cognitiva ao invés de uma esfera visual, dependendo das motivações e tendências internas, e não dos incentivos fornecidos pelos objetos. (VYGOTSKY 1991 apud DRAGO, 2009, p.109-110)

O brincar está relacionado ao desenvolvimento da percepção da memória, da afetividade, da imaginação, aprendizagem, linguagem e atenção. O brincar possui esta importância no processo de aprendizado e desenvolvimento, ou seja com tudo isso a criança sempre torna atitudes além do habitual de sua idade, de seu comportamento diário, e acaba se tornando maior do que é na realidade. Isso esta ligado aos processos mentais adquiridos e desenvolvidos no brincar, com o mundo que esta em sua volta.

[...] está ligada imediatamente á motricidade, que constitui apenas um dos momentos do processo sensório motor integral e que, somente paulatinamente, com os anos, começa a adquirir uma notável independência e a libertar-se dessa conexão parcial com a motricidade (VYGOTSKY 1991 apud DRAGO, 2009, p.109-110) 
A criança vai sendo modificada a partir do momento em que ela vais exercitando suas funções de memória, de linguagem, de afetividade, de imaginação

Nos primeiros anos de vida, a memória é uma das funções psíquicas centrais em torno da qual se organizam todas as outras funções. A análise mostra que o pensamento da criança de pouca idade é fortemente determinado por sua memória. (VYGOTSKY 1991 apud DRAGO, 2009, p.109-110)

Para Vygotsky deve se fazer com que a aptidões humanas sejam capazes de assimilar as capacidades das crianças e desenvolver o maximo de se existe para o seu desenvolvimento e a questão do processo de internalização com o conhecimento em que a criança aprende e se desenvolve ao longo do seu processo.

Quando se trata do maternal onde as crianças já são um pouco maiores e a rotina é um pouco diferente das apresentadas pelo berçário, ou seja, existem atividades durante o processo. Segundo ARANHA (1993 p. 13-14) esta é a rotina do maternal.

Período da manhã:

$>\quad$ Recepção das crianças

$>\quad$ Organização das bolsas

$>\quad$ Café da manhã

$>\quad$ Atividades Pedagógicas

$>\quad$ Higiene para o almoço

$>\quad$ Almoço

$>\quad$ Higiene

Período da tarde:

$>\quad$ Repouso

$>\quad$ Lanche

$>\quad$ Atividades pedagógicas

$>\quad$ Banho se for necessário

$>\quad$ Saída

Percebe-se que existe durante a rotina do dia a dia, atividades pedagógicas, mas que geralmente passam a ser desenvolvidas individualmente não deixando que as crianças envolvam em grupos ou que haja uma interação entre os colegas. O brincar poderia ser uma mola 
propulsora desse processo, atividades pela qual as crianças estarão aprendendo de todas as formas e desenvolvendo os aspectos mentais, motores e sócias e contribuindo com o processo de humanização das crianças.

Esse é o foco que não se trabalha nas creches atuais, a importância do processo de humanização. Segundo Mello (2007)a educação é um processo de humanização que se deve ser trabalhado na vida da criança, onde o educador é o educador é o melhor que pode fazer com que a criança compreenda a importância da socialização para o seu cotidiano.

As aquisições do desenvolvimento histórico das aptidões humanas não são simplesmente dadas aos homens nos fenômenos objetivos da cultura material e espiritual que os encarnam, mas estão ai apenas postas. Para se apropriar destes resultados para fazer deles as suas aptidões órgãos da sua individualidade a criança, o ser humano, deve entrar e relação com os fenômenos do mundo circundante através de doutros homens, isto é num processo de comunicação com eles. Assim a criança aprende a atividade adequada. Pela função este processo é, portanto um processo de educação ( MELLO, 2007 p. 88)

As educadoras por si ficam somente focadas nas necessidades do cuidar e acabam esquecendo do educar dentro de uma concepção humanizadora. O educar na creche atual é visto apenas através de um processo de alfabetização numa vertente decodificadora.

Processo de humanização esta ligado ao homem se apropriar da cultura e fazer dela parte da sua constituição, o processo de educação é um humanizador que leva as apropriações da cultura ao homem, e a riqueza cultural. Assim, oferecendo as crianças a riquezas que o homem produziu ao longo da historia, oferecendo também a capacidade de ouvir, de falar, de respeitar, de conviver com as diferenças e ser mais críticos diante do mundo que os cercam.

Mesmo com tantos estudos sobre a creche e sua importância no processo de educação, atualmente ela é vista sobre a ótica de somente cuidar, e de um educar massificador, voltado para o exercício da escrita e da leitura decodificadora, não exercendo seu papel de formar crianças com atitudes e opiniões.

Nessa perspectiva, os educadores como mediadores em potencial precisam ter a consciência de que a educação é um processo de humanização, possibilitando formar cidadãos mais críticos, políticos e autônomos. 


\section{DISCUSSÃO}

O espaço da creche ainda carrega consigo resíduos históricos assistencialistas, priorizando apenas o cuidar da criança e tendo uma visão do educar pautado nos modismos educacionais e numa visão antecipatória do desenvolvimento, onde o processo de humanização não é a prioridade.

A educação como processo de humanização, significa direciona-la a realizar praticas educativas que levem as crianças a máxima apropriação da cultura produzida historicamente pela humanidade, sendo de extrema importância desde o trabalho nas creches. Nesse sentido, essa relação com os objetos culturais e ações sobre eles trazem significativas mudanças no desenvolvimento infantil, até mesmo enquanto um cidadão crítico e participativo da sociedade. A relação que a criança constrói com o mundo é fundamental para seu desenvolvimento tanto cognitivo quanto social.

\section{CONSIDERAÇÕES FINAIS}

Foi feita uma pequena analise sobre a creche mostrando que ela ainda é vista como um depósito de crianças onde os pais as deixam para poderem trabalhar, visando somente o ato de prestar assistência e deixando de lado o aspecto da educação para o desenvolvimento integral da criança, num processo humanizador.

Por meio da pesquisa bibliográfica realizada sobre a temática vimos como foi o surgimento da creche no Brasil, destacando algumas questões que a impulsionaram como: a necessidade de pais que não tinham com quem deixar seus filhos enquanto trabalhavam fora de casa, sublinhando também a necessidade das mulheres enfrentarem o mercado de trabalho.

Frequentar a creche considerando ser um espaço que potencialize as crianças para o desenvolvimento pleno da criança é crucial. Para isso torna-se necessário que as creches ofereçam estrutura física e humana adequada. As creches, tanto públicas quanto particulares, não possuem estrutura física para abrigar o grande número de crianças que as freqüentam. As salas são pequenas e as crianças acabam por passar o dia dentro delas, sem espaço para brincar e se locomover. A quantidade de funcionários é pequena em relação ao numero de crianças, que acabam por ficar sem a atenção necessária de um adulto em momentos como banho e alimentação, que também são atividades importantes para o desenvolvimento infantil. 
Além de poucos funcionários, a formação dos mesmos é escassa, portanto deixam de realizam atividades significativas e que contribuam para o desenvolvimento das potencialidades infantis.

Para concluirmos, a relação ensino aprendizagem num processo humanizador acaba sendo esquecido, prejudicando o desenvolvimento integral da criança e violando seus direitos, o direito a educação e a apropriação da cultura humana.

\section{REFERÊNCIAS}

ARANHA, M. L. A. R. Desenvolvimento infantil na creche. São Paulo: Loyola, 1993.

DRAGO, D. RODRIGUES S.P Contribuições de Vygotsky para o desenvolvimento da criança no processo educativo: algumas reflexões, dez.2009. Revista Face $n^{\circ} 3$ : http://www.facevv.edu.br/revista/03/artigohtm acesso em 06 abril 2010.

MELLO, S. A. Infância e humanização: algumas considerações na perspectiva histórico-cultural. Revista do Centro de Ciências da Educação, Florianópolis: v. 25, n. 1, p. 83-104, jan/jun., 2007.

MERISSE A. Origem das instituições de atendimento à criança: o caso das creches. P.25-51. In: Merisse A, Justo JS, Rocha LC da, Vasconcelos MS. Lugares da infância: reflexões sobre a história da criança na fábrica, creche e orfanato. São Paulo (SP): Arte Ciência; 1997. 